\title{
Carbonaceous Soot from Thermal Decomposition of Kerosene: A Pioneering Report for Paint Preservation
}

\author{
Olayide F. Obidi, Onyiye V. Okoli, Simon C. U. Nwachukwu \\ Department of Microbiology, University of Lagos, Nigeria
}

Received $27^{\text {th }}$ August 2016, Accepted $10^{\text {th }}$ November 2016

DOI: 10.2478/ast-2018-0004

*Corresponding author

O.F.Obidiemail: laideob@yahoo.com

Tel: +2348034720933

\begin{abstract}
Bacterial resistance to conventional paint biocides is widely documented. However, an investigation regarding the preservative potential of carbonaceous soot as a viable alternative is novel. Fresh paint samples (SA, SB and SC) were collected in duplicates from a reputable paint manufacturing company in Lagos, Nigeria. SA was produced with conventional paint biocide, SB and SC were without biocide. All samples were inoculated with $0.032 \times 10^{6} \mathrm{cfu} / \mathrm{mL}$ of Pseudomonas aeruginosa PA01 (NC 002516.2) previously isolated from spoilt paints and identified by the $16 \mathrm{~S}$ rDNA analysis. SB was supplemented with crude soot $(10 \mathrm{~g} / \mathrm{L}$ of distilled water) at $200 \mathrm{~mL} \mathrm{v} / \mathrm{v}$. The preservative efficiency of soot was investigated by monitoring the bacterial population (BP), optical density $\left(\mathrm{OD}_{600 \mathrm{~nm}}\right)$, viscosity (VIS), the transmittance (TR) and specific gravity (SG) of the samples bi-weekly for 14 weeks. BP increased drastically from 0.032-31.61 x10 $0^{6}$ and from 0.032$112.93 \times 10^{6}$ in SA and SC respectively. In contrast, SB increased from 0.032- $24.63 \times 10^{6}$ by week 4 but reduced from $24.63-10.95 \times 10^{6}$ by week 14 . The OD of SA increased from 1.55 to 1.98 by week 8 and decreased to 1.74 by week 14 SB had a decrease from 1.60 to 1.49 by week 4 and increased to 1.63 by week 14, while SC increased from 1.59 to 2.54 by the 14th week.TR increased from 1.80 to 2.30 and 1.25 to 2.20 in SA and SC respectively. In contrast, TR decreased from 2.00 to 1.25 in SB. The viscosity and specific gravity values of all the samples decreased with time with the highest decrease observed in SC and the lowest in SB. The test crude soot showed preservative potential in paints.
\end{abstract}

Keywords: Paints; Soot; Pseudomonas aeruginosa; Preservation 


\subsection{Introduction}

Paints are uniformly dispersed mixtures which are typically stored, sold, and applied as a liquid but dries to a solid film (Vore and Pierce, 1995) after application. Their primary function is to protect a surface to which they are applied from corrosion, oxidation, environmental weathering or other types of deterioration (Briggs, 1980; Adeleye and Adeleye, 1999; Cho et al., 2005). However, in addition to these functions, they also give identification and beauty to surfaces. The tendency towards corrosion of most important metals, such as steel, aluminium, zinc and galvanized steel, can be controlled in an effective manner by organic coatings (Del Amo et al., 2002) such as paints. Water-based paints, though are most popular in recent times are prone to biodegradation because of their aqueous nature and presence of organic materials which serve as nutrients and carbon sources for microbial proliferation both in-can and on the dry paint film (Da Silva, 2003; Obidi et al., 2010).

Paints contain basic ingredients such as a binder, pigment, additive and solvent (Dey et al., 2004). The binders or resins are polymers that form a matrix to hold the pigment in place. The three most important binders used in modern paints are acrylic polymers, alkyd polymers, and epoxy polymers all of which are subject to biodegradation. Biodeterioration of paints seriously compromises the adhesion and durability of the paint as well as its decorative function (Da Silva, 2003). Unfortunately, microbial contamination of paints can be from a number of sources such as raw materials, manufacturing plant process units and packaging materials (Gillatt, 1992). The shelf life of water-based paints is highly influenced by several factors such as initial microbiological quality of raw materials, packaging materials and the manufacturing plant itself (Obidi et al., 2009).

The role of microorganisms has been shown to be prominent in the degradation of paints properties as well as durability of paint films (Obidi et al., 2010).Biodeterioration of paint falls into two general categories: enzymatic degradation of protein and cellulosic thickeners that produce an irreversible viscosity loss in latex emulsion paints while still in the container, and microbial disfigurement and deterioration of both water-thinned and solvent thinned paint films. Enzymes catalyzing the degradation of protein and cellulosic thickeners may be introduced into the paint through contaminated raw materials, storage tanks, and other equipment or be released by bacteria (and less frequently, yeast) growing actively in the liquid paint (El-Sayed et al., 1996). The susceptibility of paint films to attack by microorganisms is determined in part by the chemical nature of the non volatile binder, the choice of pigmentation, and the pigment volume concentration. To a much greater degree, however, the susceptibility or resistance of a paint film to a biological attack is determined by the presence and concentration of antimicrobial agents (Contant et al., 2010).Previous studies have revealed that biocides can enhance the shelf life of paints (Voulvouliset al., 2000; Albanis et al., 2002; Martinez et al., 2001).However, public health and environmental concerns have limited the use of biocides as many bacterial strains develop resistance and require higher than safety level doses to kill microbes.

Therefore, in this study, we report a rare study focusing on the preservative potential of crude soot in water based paints in relation to painting physicochemical parameters with a view to developing an environmentally friendly and cost-effective formulation technology. Crude soot was selected as a potential biocide because of its robustness, availability and relative ease of scale-up.

\subsection{Materials and Methods}

\subsection{Sample Collection}

Freshly prepared paint samples (200 mL each) were aseptically collected in sterile air-tight containers after production from a paint manufacturing industry in Lagos, Nigeria. Spoilt paint samples with the characteristic foul smell, discoloration, reduced viscosity and gassing were also obtained. The samples were labelled appropriately and taken to the laboratory for analyses.

\subsection{Microbiological Analysis}

\section{Isolation of Pseudomonas aeruginosa from spoilt paint samples}

Nutrient agar (NA) was prepared as per the manufacturer's instruction. Ten-fold serial dilution of spoilt paint sample was carried out. Aliquots of $0.1 \mathrm{~mL}$ from selected dilutions were plated onto already solidified NA plates and spread evenly with a sterile hockey stick. Subsequently, the plates were incubated aerobically at $37{ }^{\circ} \mathrm{C}$ for $24 \mathrm{~h}$. The plates were examined for developed colonies which were purified and preserved at $4{ }^{\circ} \mathrm{C}$ on NA slants (Guglielminetti et al., 1994).

\section{Identification of Bacteria Using API}

The $P$. aeruginosa colonies that developed on nutrient agar plates were Gram stained and identified based on the analytical profile index (API) using the (API) 20 NE kit (bioMerieux, Marcy l'Etoile, France).

\subsection{Total DNA Extraction}

Overnight suspension of purified isolate in peptone broth was used for the $16 \mathrm{~S}$ rDNA extraction, polymerase chain reaction (PCR) and sequencing reaction. Genomic DNA was extracted from pure cultures sing theQIAGENQIAamp DNA Mini Kit (250) cat no 51306 by a modification of the method of McPherson and Moller, (2007). Elution buffer solution (10 mMTris-Cl, 0.5 mM EDTA; pH 9.0) was placed into $70^{\circ} \mathrm{C}$ water bath, $180 \mu \mathrm{L}$ of Animal Tissue Lysis buffer (sodium dodecyl sulphate at $2.5-10 \%$ ) was added to the isolate. Subsequently, $20 \mathrm{ul}$ of proteinase $\mathrm{K}$ was then added and the sample was incubated at $56{ }^{\circ} \mathrm{C}$ until it was completely lysed. Then, the sample was vortexed occasionally and complete lysis was achieved within 3 h. Centrifuging was carried out and $200 \mu \mathrm{L}$ of Lysis buffer solution (Guanidinium chloride at $25-50 \%$ ) was added after 15 seconds of vortexing. The tube was then incubated at $70{ }^{\circ} \mathrm{C}$ for $10 \mathrm{~min}$ followed by centrifugation to collect condensation. 96$100 \%$ ethanol $(230 \mu \mathrm{L})$ was added to the tube and further mixed by vortexing for 30 secs. The sample was carefully applied to QIAamp spin column and then centrifuged at $6000 \mathrm{~g}$ for $1 \mathrm{~min}$. The spin column was placed in a clean $2 \mathrm{ml}$ collection tube and the filtrate was discarded. $500 \mu \mathrm{L}$ of wash buffer (Guanidinium chloride at $50-100 \%$ was added and the mix was spun at $6000 \mathrm{~g}$ for $1 \mathrm{~min}$, placed in collection tube filtrate. $500 \mu \mathrm{L}$ of wash buffer (Sodium azide at $0.1 \%$ ) was then added to the mix, spun at $6000 \mathrm{~g}$ for $1 \mathrm{~min}$, placed in a collection tube and the filtrate discarded. The sample was subsequently centrifuged at full speed for 3 min and column was placed in the labelled $1.5 \mathrm{ml}$ tube. $200 \mu \mathrm{L}$ of the preheated $\left(70{ }^{\circ} \mathrm{C}\right)$ elution buffer $(10 \mathrm{mM}$ Tris- $\mathrm{HCl} ; 0.5 \mathrm{mM}$ EDTA; pH 9.0) was added. The tube was incubated at $\left(70^{\circ} \mathrm{C}\right)$ for $5 \mathrm{~min}$ and then centrifuged at $6000 \mathrm{~g}$ rpm for $1 \mathrm{~min}$. 
The filtrate solution $(-200 \mu \mathrm{L})$ was placed back into the spin column. Again, $200 \mu \mathrm{L}$ of the preheated $\left(70{ }^{\circ} \mathrm{C}\right)$ elution buffer 10 $\mathrm{mM}$ Tris-Cl; $0.5 \mathrm{mM}$ EDTA; pH 9.0) was added. The tube was incubated at $\left(70{ }^{\circ} \mathrm{C}\right)$ for $5 \mathrm{~min}$ and then centrifuged at $6000 \mathrm{~g} \mathrm{rpm}$ for $1 \mathrm{~min}$. The spin column was discarded followed by running of agarose (McPherson and Møller, 2007).

\subsection{PCR Amplification}

The extracted DNA was then used for PCR reaction. Close to full-length 16S rDNA sequences were amplified by PCR using the 27F (AGAGTTTGATCMTGGCTCAG) and 1525R (AAGGAGGTGWTCCARCCGCA). The $16 \mathrm{sF}$ is $27 \mathrm{~F}$ and the $16 \mathrm{sR}$ is $1525 \mathrm{R}$. The PCR cocktail mix consisted of $1.0 \mu \mathrm{L}$ of $10 \times$ PCR buffer, $1.0 \mu \mathrm{L}$ of $25 \mathrm{mM} \mathrm{MgCl} 2,0.5 \mu \mathrm{L}$ each of $5 \mathrm{pMol}$ forward and reverse primers, $1.0 \mu \mathrm{L}$ of Dimethyl sulfoxide (DMSO), $0.8 \mu \mathrm{L}$ of $2.5 \mathrm{Mm}$ DNTPs, $0.1 \mu \mathrm{L}$ of Taq polymerase 5 $\mu \mathrm{g} / \mathrm{ul}, 2.0 \mu \mathrm{L}$ of $10 \mathrm{ng} / \mu \mathrm{L}$ template DNA and $3.1 \mu \mathrm{L}$ of $\mathrm{H}_{2} \mathrm{O}$ to a total volume of $10 \mu \mathrm{L}$. A program of thermal cycling was carried out thus: initial denaturation at $94{ }^{0} \mathrm{C}$ for $5 \mathrm{~min}$; 36 cycles consisting of 30 secs at $94{ }^{\circ} \mathrm{C}, 30$ secs at $56{ }^{\circ} \mathrm{C}$, and 45 secs at 72 ${ }^{0} \mathrm{C}$, followed by a final extension step consisting of $7 \mathrm{~min}$ at 72 ${ }^{0} \mathrm{C}$. The resulting amplicon was loaded for analysis on $1.5 \%$ agarose gel electrophoresis followed by subsequent purification of the PCR product (McPherson and Møller, 2007).

\subsection{PCR Product Purification}

Absolute ethanol $(20 \mu \mathrm{L})$ was added to the PCR product which was then incubated at room temperature for $15 \mathrm{~min}$. Following the incubation, it was centrifuged for $15 \mathrm{~min}$ at $10000 \mathrm{rpm}$ and the supernatant decanted. Subsequently, it was spun down at $10000 \mathrm{rpm}$ for another $15 \mathrm{~min}$ and $40 \mu \mathrm{L}$ of $70 \%$ ethanol was added to the mix. The supernatant was decanted and then air dried. Ultrapure water $(10 \mu \mathrm{L})$ was added and the amplicon was checked using 1.5\% agarose (McPherson and Møller, 2007).

PCR product was used for the sequencing reaction with the BigDye ${ }^{\circledR}$ Terminator v3.1 Cycle Sequencing Kit. After which the sequencing reaction was purified. The product from the purification process was loaded on the $3130 \times 1$ genetic analyzer from Applied Biosystems to produce the sequences.

\subsection{Sequence Analysis}

Sequencing was carried out using primer 518r (50-GTA TTACCG CGG CTG CTG-30) and 338f (50-ACT CCT ACG GGA GGC AGC-30) (Kwon et al., 2005) and sequences of the 16SrDNA between 362 and 484bp (average 451 bp) were submitted to the Advanced BLAST search program of the National Center for Biotechnology Information (NCBI) to determine their alignments with closely related organisms. The related sequences were preliminarily aligned with the default settings of CLUSTAL W (Thompson et al., 1994) and submitted to SEQ-MATCH and CLASSIFIER program of the Ribosomal Database Project (RDP) to obtain a preliminary list of closest phylogenetic neighbours.

\subsection{Inoculum Preparation}

Freshly prepared bacterial suspension of $P$. aeruginosa PA01was grown in nutrient broth (NB). The cultured bacteria were standardized to reach the concentration of $3.2 \times 10^{4}$ colony forming units per millilitre (cfu/mL). The optical density and transmittance of the inoculum were determined with the aid of a spectrophotometer at $600 \mathrm{~nm}$ to be 0.035 .

\subsection{Collection of Lamp Soot}

The regular kerosene lamp was obtained from Bariga Market, Lagos, Nigeria and charged with kerosene (a hydrocarbon). The lamp was allowed to absorb the kerosene and subsequently lit with a match stick and allowed to burn. A glass beaker $500 \mathrm{ml}$ was placed over the flame of the lamp to collect emitted soot from the lamp. The lamp wick was previously cleaned with detergent followed by acetone before drying at $70{ }^{\circ} \mathrm{C}$. The collected soot was kept for further use by wrapping in aluminium foil without exposure to light (Dikio, 2011).

\subsection{Experimental Set-Up}

The experiment was carried out for 3 months at room temperature and observed bi-weekly. Physicochemical properties including metal concentration, viscosity, specific gravity, optical density, transmittance and $\mathrm{pH}$ were evaluated for all the samples at day zero and biweekly thereafter. $100 \mathrm{~mL}$ of freshly prepared inoculum at a population density of $3.2 \times 10^{4} \mathrm{cfu} / \mathrm{mL}$ was inoculated into all beakers designated as SA1, SA2, SB1, SB2, SC1 and SC2 where SA1 and SA2 are duplicates containing freshly prepared paint samples incorporated with biocide during production. SB1 and SB2 are duplicates containing freshly produced paint samples without biocide incorporation during production but containing $200 \mathrm{ml}$ of $0.2 \mathrm{~g} / \mathrm{L}$ crude soot obtained from kerosene. SC1 and SC2 are duplicates containing freshly prepared paint samples without biocide and crude soot. After inoculation of the samples, the physicochemical parameters were analyzed.

\subsection{Physicochemical Analysis}

Atomic absorption spectrometry (AAS) was used to measure the concentration of lead $(\mathrm{Pb})$ and chromium $(\mathrm{Cr})$ in the paint samples as described by Levinson, (2002) using Perking Elmer Analyst 200 flame Atomic Absorption Spectrophotometer equipped with acetylene gas. Appropriate standards of $\mathrm{Pb}$ and $\mathrm{Cr}$ were used as reference analytes for calibration. The viscosity of the paint samples was determined using a viscometer $\left(\mathrm{EZ}^{\mathrm{TM}}\right.$ / ZAHN, ASTM \#3) as described by Rammohan and Yassen, (2003). The specific gravity of paint samples was monitored with the aid of pycnometer relative to the density of water as described by Ohwoavworhua and Adelakun (2005). The $\mathrm{pH}$ of paint samples was determined with the use of an electronic digital $\mathrm{pH}$ meter (Model: Jenway M50/Rev CE 350EU) in 1: 200 solution of the paint samples in distilled water. The $\mathrm{pH}$ meter was calibrated using phthalate buffer $(\mathrm{pH}, 4.0)$ and phosphate buffer solutions (pH 7.0). The Optical Density and Transmittance were determined with the use of a spectrophotometer (Spectrumlab $\mathrm{S} 23_{\mathrm{A}}$ ). The photoelectric colorimeter used in the study was standardized by adjusting it to read $100 \%$ light transmittance with $5 \mathrm{ml}$ of distilled water in a $1 \mathrm{~cm}$ glass cuvette placed in it at 600 $\mathrm{nm}$. The bottom scale displayed the absorbance and the top scale, $\%$ transmittance. The test was carried out bi-weekly for three months and the displayed results were recorded. The specific gravity of paint samples was carried out by pycnometer as described by Ohwoavworhua and Adelakun (2005). 
Note that:

SA: Sample A (Mean values of SA1 and SA2), paint produced with biocide + microorganism

SB: Sample B (Mean values of SB1 and SB2), paint produced without biocide + crude soot + microorganism

SC: Sample C (Mean values of SC1 and SC2) paint produced without biocide + microorganism

\subsection{Results and Discussions}

In other to investigate the effectiveness of crude soot in the preservation of in-can paints, the mean changes in microbial population densities of the samples were evaluated over the fourteen-week study period. It was observed that the microbial population density decreased appreciably in SB which was inoculated with soot compared with the control samples SC and samples with conventional paint biocide (SA) where the population density increased over the study period (Fig. 1). In $\mathrm{SB}$, the microbial population increased in the $2^{\text {nd }}$ and $4^{\text {th }}$ week then decreased all through the 14 -week study period. This showed an initial lag phase and a terminated log phase of bacterial growth. The initial inoculated population of $P$. aeruginosa PA01 was $0.032 \times 10^{6} \mathrm{cfu} / \mathrm{ml}$, this increased to 31.61 x $10^{6} \mathrm{cfu} / \mathrm{ml}, 10.95 \times 10^{6} \mathrm{cfu} / \mathrm{ml}$ and $112.93 \times 10^{6} \mathrm{cfu} / \mathrm{ml}$ in SA, SB and SC respectively. The effect of soot on the physicochemical properties of paints is critical to its shelf life. Hence, optical density (OD), the transmittance (TR), specific gravity (SG), viscosity (VIS) and heavy metal concentration were evaluated over the study period. Figures $2-6$ show the mean changes in physicochemical parameters during the study. The optical density at $600 \mathrm{~nm}$ in SA increased from 1.55 to 1.98 in the 8 th week and decreased to 1.74 in the 14th week (Fig. 2). This suggests the activity of the incorporated conventional biocide which was slow at the onset but eventually performed weakly over time. The $\mathrm{pH}$ ranged from $7.78-8.15,7.67-8.73$ and $7.67-8.28$ for SA, SB and SC respectively (Fig. 3.). The $\mathrm{pH}$ of all the samples (SA, SB and SC) fell within the optimal $\mathrm{pH}$ limits of growth of $P$. aeruginosa PA01 as shown in Fig. 3. The viscosity and specific gravity values of all the samples decreased with time with the highest decrease observed in SC and the lowest in SB (Fig. 4 \& 5). The specific gravity of SA decreased from 1.055 to 0.62 ; SB decreased from 1.40 to 0.80 ; while SC decreased from 1.31 to 0.62 . Viscosity values of SA decreased from 266.4 to 26.9 ; SB decreased from 750.9 to 236.8 ; while SC decreased from 548.7 to 96.4.Transmittance in SA decreased from 1.80 to 1.55 in the $6^{\text {th }}$ week and increased to 2.30 in the $14^{\text {th }}$ week. In SB, transmittance decreased from 2.00 to 1.25 ; while in $\mathrm{SC}$, it increased from 1.25 to 2.20 (Fig. 6.). The atomic absorption spectrometry (AAS) of heavy metals detected no trace of lead, but $\mathrm{Cr}$ in SB. AAS value of SB for chromium was 69.0 $\mu \mathrm{g} / \mathrm{g}$ in the first week and reduced to $58.3 \mu \mathrm{g} / \mathrm{g}$ by the $14^{\text {th }}$ week.

This paper describes the possible preservative potentials of crude soot in paints. Few such studies have been reported thus far, and this may be the first one that investigated the antibacterial properties of soot for paint preservation. The emergence of biocide-resistant strains has put biocides at a disadvantage mainly because higher doses, which pose environmental risks (Edge et al., 2001) are required to combat paint spoilage bacteria. Furthermore, legislative directives also ensure the reduction in the amount of biocides released into the environment (Chau et al., 1997; Edge et al., 2001). As a result, alternative preservatives are required which are cheap, available and less toxic. In developing countries like Nigeria, the synthesis of nanoparticles for antibacterial purposes may not be readily feasible due to the cost of production as well as the necessary infrastructure required. As a result, cheap and less complex techniques like thermal decomposition of commercial kerosene can be explored for bactericidal purposes.

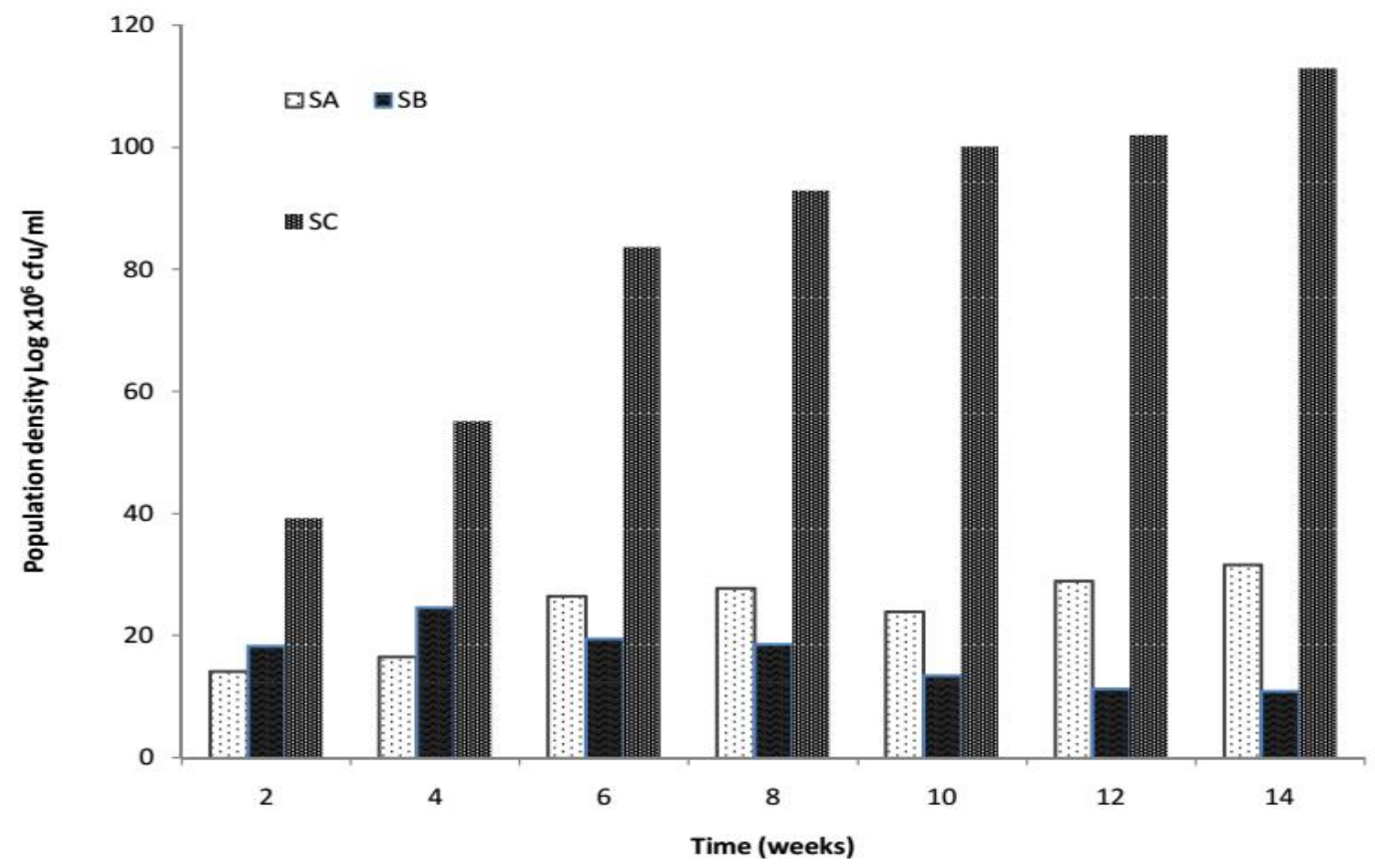

Fig. 1: Mean changes in microbial population density in paint samples over a period of 14 weeks 


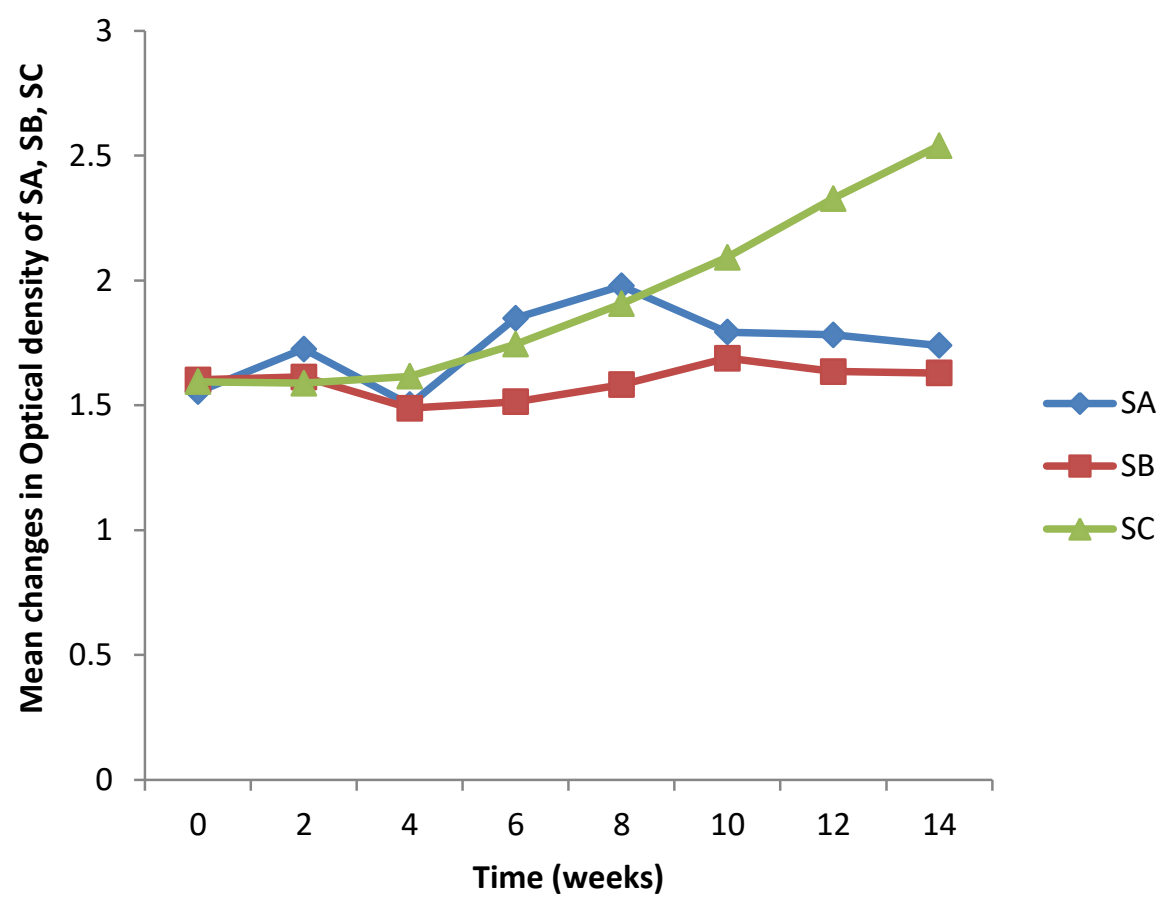

Fig. 2: Mean changes in optical density of paint samples over a period of 14 weeks.

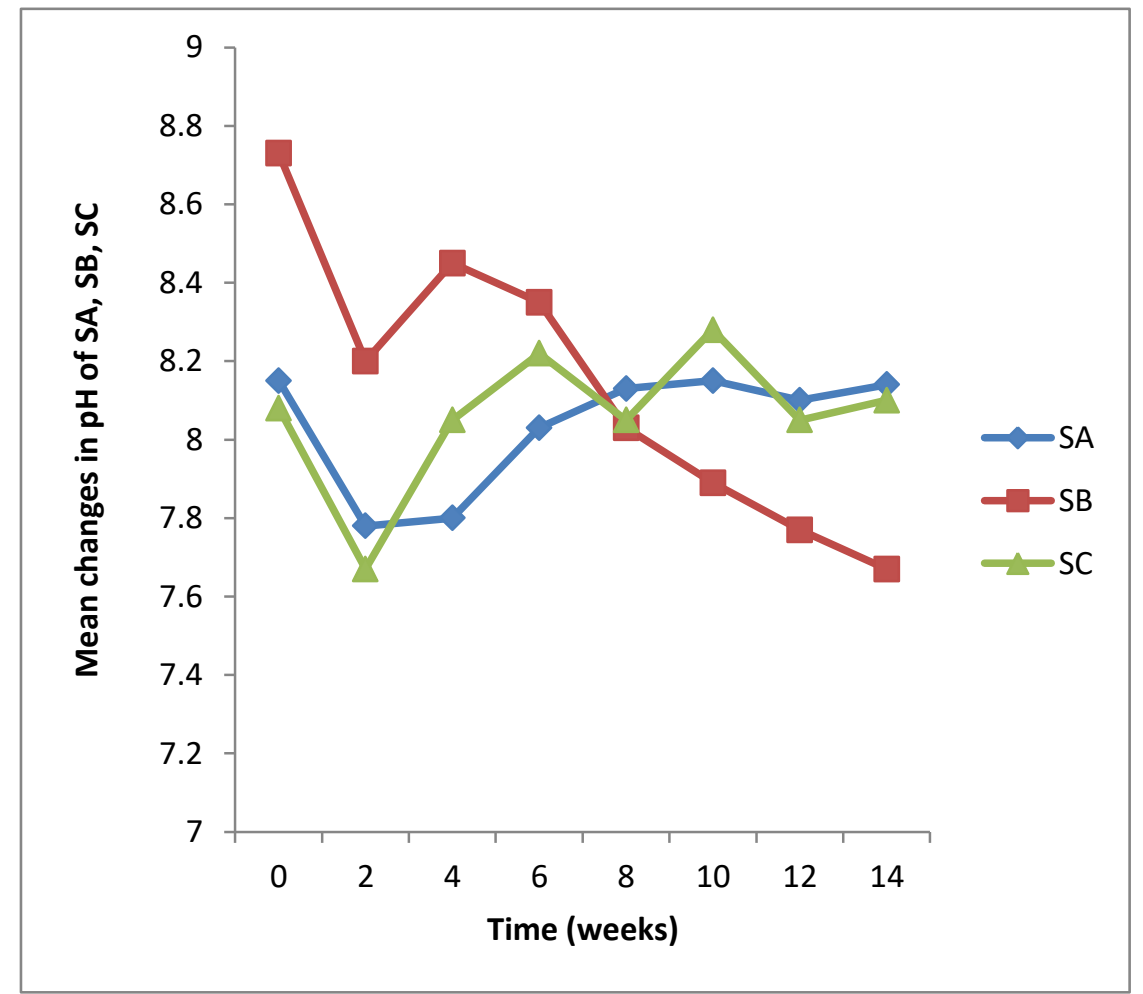

Fig. 3: Mean changes in $\mathrm{pH}$ of paint samples over a period of 14 weeks 


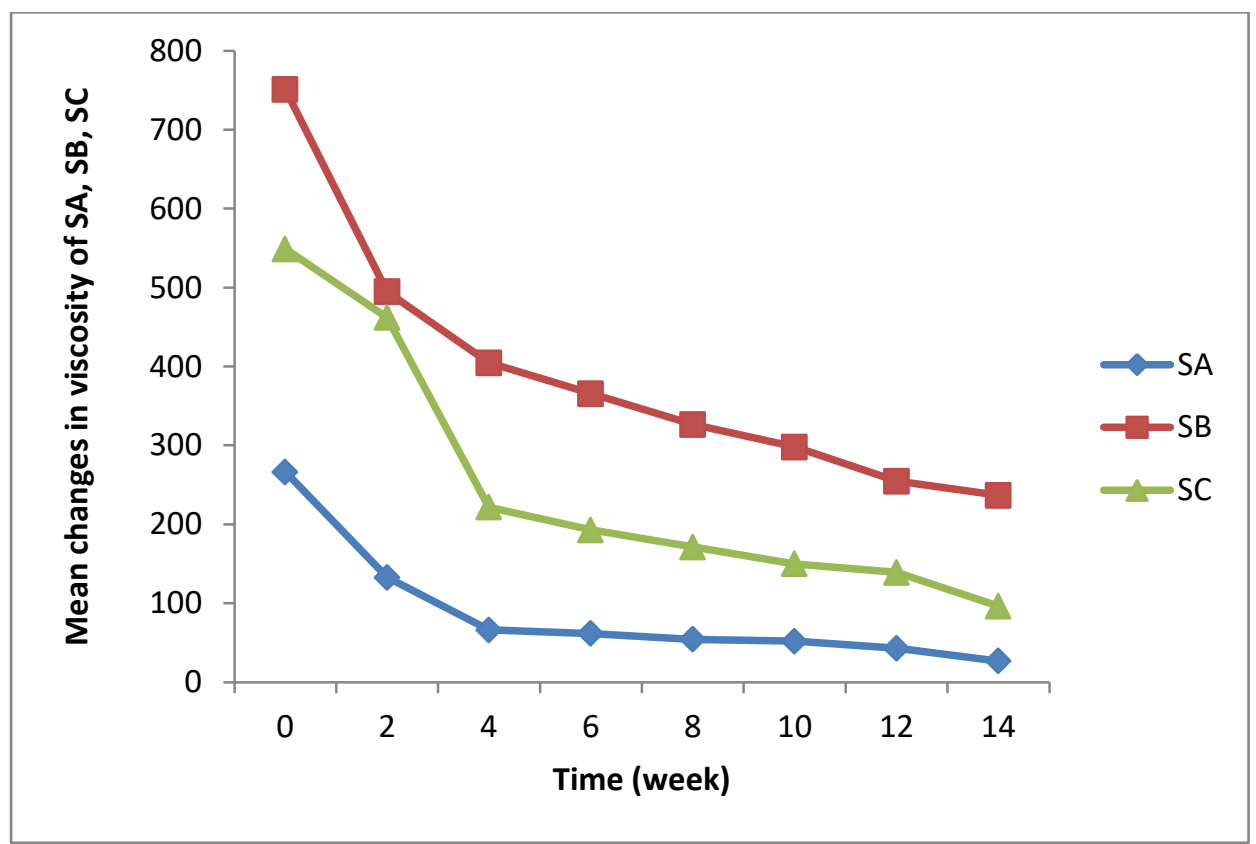

Fig. 4: Mean changes in viscosity of paint samples over a period of 14 weeks.

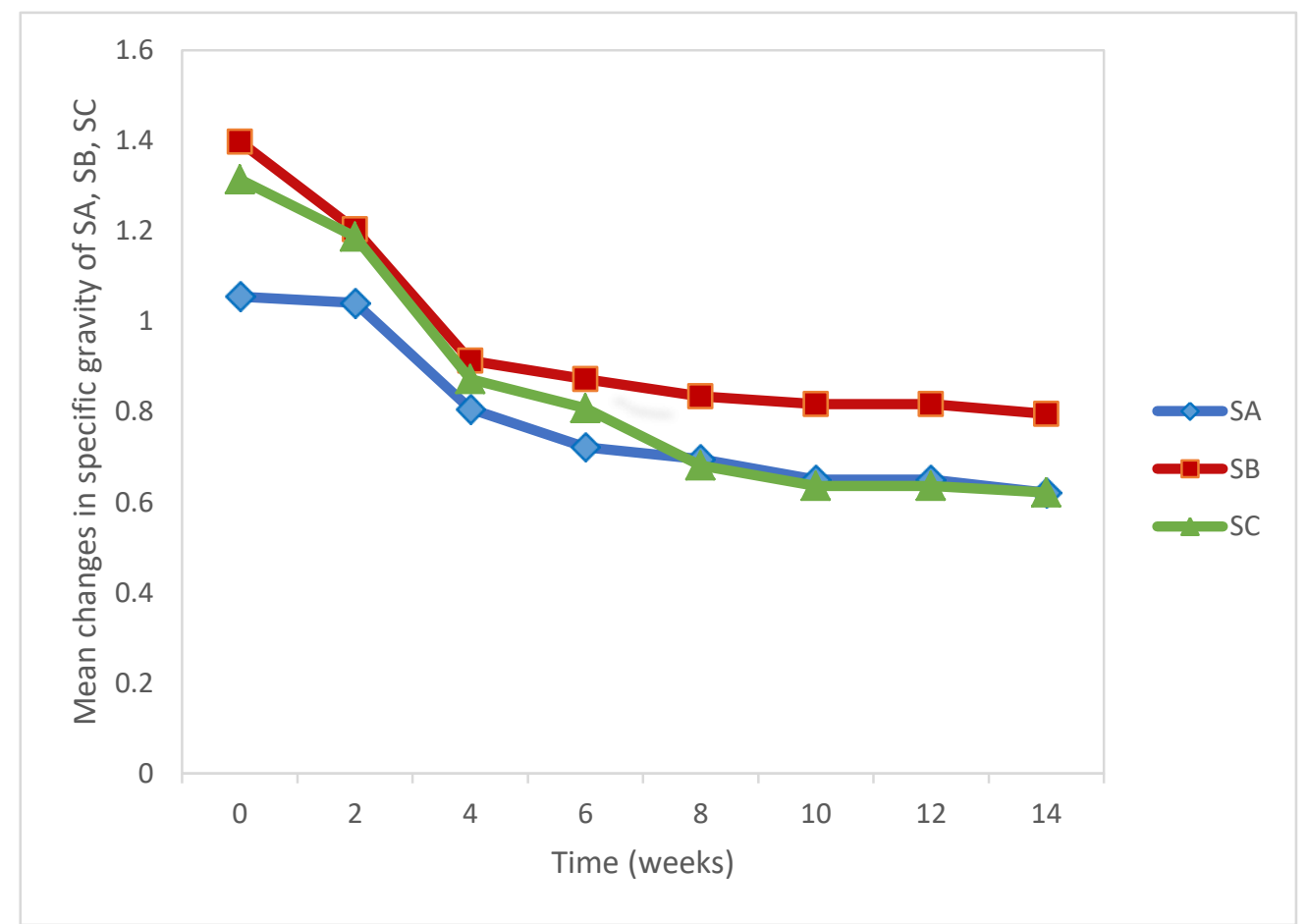

Fig. 5: Mean changes in specific gravity of paint samples over a period of 14 weeks 


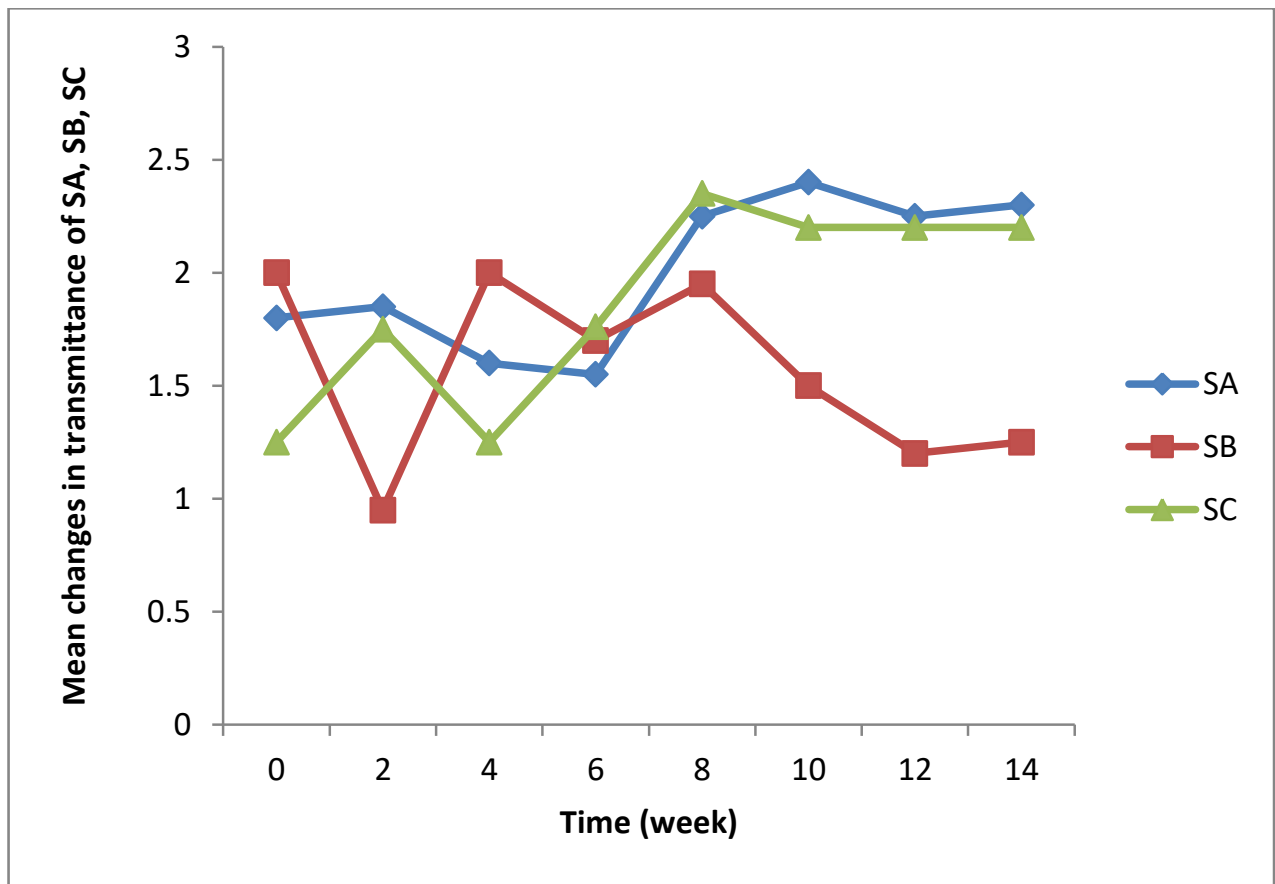

Fig. 6: Mean changes in transmittance of paint samples over a period of 14 weeks

\subsection{Conclusion}

Crude soot obtained from thermal decomposition of kerosene demonstrated preservative activity against Pseudomonas aeruginosa, PA01, isolated from spoilt paints and could be adapted for use in paint formulation for inhibiting spoilage microbes in paints.

\subsection{Conflict Of Interest}

All Authors have declared that there are no conflicts of interest.

\section{Acknowledgements}

The authors are extremely thankful to Dr L. A. Adams of Chemistry Department, University of Lagos, Nigeria for technical support in the preparation of crude soot. The authors also acknowledge Dr S. Smith of the Nigerian Institute for Medical Research (NIMR), Yaba, Lagos for the use of her laboratory.

\section{Author's Contribution}

Conception: Nwachukwu, S.C.U. and Obidi, O. F

Design: Obidi, O. F.

Execution: Obidi, O. F. and Okoli, O. V.

Interpretation: Obidi, O. F. and Okoli, O. V.

Writing: Obidi, O. F. and Okoli, O. V.

\section{References}

Adeleye, I., Adeleye, O., 1999, Isolation and identification of microbes associated with paints and weathered painted walls. J. Sci. Res. Dev 4, 71-76.

Alba, J., Conde, E., Pérez-Guevara, F., 2003, Degradation of the main components of cellulose-paint thinner by the mould Scopulariopsis brevicaulis cultured on rice hulls. Letters in applied microbiology 37, $7-11$.

Albanis, T., Lambropoulou, D., Sakkas, V., Konstantinou, I., 2002, Antifouling paint booster biocide contamination in Greek marine sediments. Chemosphere 48, 475-485.

Bastos, F.S., Castro, P.M., Ferreira Jorge, R., 2003, Biological treatment of a contaminated gaseous emission from a paint and varnish plantfrom laboratory studies to pilot-scale operation. Journal of Chemical Technology and Biotechnology 78, 1201-1207.

Briggs, M., 1980, Emulsion Paint Preservation, Factory practice and Hygiene. Paint Research Association Technical Report.

Chau, Y., Maguire, R., Brown, M., Yang, F., Batchelor, S., 1997, Occurrence of organotin compounds in the Canadian aquatic environment five years after the regulation of antifouling uses of tributyltin. Water quality research journal of Canada 32, 453-521.

Cho, J.D., Ju, H.T., Hong, J.W., 2005, Photocuring kinetics of UVinitiated free-radical photopolymerizations with and without silica nanoparticles. Journal of Polymer Science Part A: Polymer Chemistry 43, 658-670.

Chung, H., Ku, M.-S., Lee, J.-S., 1999, Comparison of near-infrared and mid-infrared spectroscopy for the determination of distillation property of kerosene. Vibrational spectroscopy 20, 155-163. 
Contant, S., Caritá Júnior, G., Machado, P., Lona, L., 2010, Evaluation of the effect of dry-film biocides on paint film preservation using neural networks. Brazilian Journal of Chemical Engineering 27, 643-651.

Da Silva, V., 2003, Microbial deterioration of paints. Microbiologist 4, 43.

Del Amo, B., Romagnoli, R., Deyá, C., González, J., 2002, High performance water-based paints with non-toxic anticorrosive pigments. Progress in Organic Coatings 45, 389-397.

Dey, B., Hashim, M., Hasan, S., Gupta, B.S., 2004, Microfiltration of water-based paint effluents. Advances in Environmental Research 8, 455-466.

Dikio, E.D., 2011, Morphological characterization of soot from the atmospheric combustion of kerosene. Journal of Chemistry 8, 10681073 .

Edge, M., Allen, N., Turner, D., Robinson, J., Seal, K., 2001, The enhanced performance of biocidal additives in paints and coatings. Progress in Organic Coatings 43, 10-17.

El-Sayed, A.H.M., Mahmoud, W.M., Davis, E.M., Coughlin, R.W., 1996, Biodegradation of polyurethane coatings by hydrocarbon-degrading bacteria. International biodeterioration \& biodegradation 37, 69-79.

Gillatt, J., 1992, Bacterial and fungal spoilage of waterborne formulations. Surface coatings international 75, 387-392.

Guglielminetti, M., Morghen, C.D.G., Radaelli, A., Bistoni, F., Carruba, G., Spera, G., Caretta, G., 1994, Mycological and ultrastructural studies to evaluate biodeterioration of mural paintings. Detection of fungi and mites in frescos of the monastery of St damian in assisi. International biodeterioration \& biodegradation 33, 269-283.

Kwon, H.-S., Yang, E.-H., Lee, S.-H., Yeon, S.-W., Kang, B.-H., Kim, T.-Y., 2005, Rapid identification of potentially probiotic Bifidobacterium species by multiplex PCR using species-specific primers based on the region extending from 16S rRNA through $23 \mathrm{~S}$ rRNA. FEMS microbiology letters 250, 55-62.

Martinez, K., Ferrer, I., Hernando, M., Fernández-Alba, A.R.g., Marcé, R.M., Borrull, F., Barcelo, D., 2001, Occurrence of antifouling biocides in the Spanish Mediterranean marine environment. Environmental technology 22, 543-552.

McPherson, M., Moller, S., Graham, A. 2000. PCR; The Basics Bios (Scientific Publishers Ltd).

Ohwoavworhua, F., Adelakun, T., 2005, Phosphoric acid-mediated depolymerization and decrystallization of $\alpha$-Cellulose obtained from corn cob: preparation of low crystallinity cellulose and some physicochemical properties. Tropical Journal of Pharmaceutical Research 4, 509-516.

Rammohan, R., Yassen, M., 2003, Determination of intrinsic viscosity by single specific viscosity measurements. J. Appl. Poly. Sci 31, 25012508 .

Reilly, J.A., 1991, Celluloid objects: their chemistry and preservation. Journal of the American Institute for Conservation 30, 145-162.

Thompson, J., 1994, Improving the sensitivity of progressive multiple sequence alignment through sequence weighting, position-specific gap penalties and weight matrix choice. Nucleic Acids Res 22, 46734680 .
Varghese, S., Kuriakose, S., Jose, S., 2013, Antimicrobial activity of carbon nanoparticles isolated from natural sources against pathogenic Gram-negative and Gram-positive bacteria. Journal of Nanoscience 2013.

Vore, R., Pierce, J., 1995, 8 Preservation of paint formulations, In: Preservation of Surfactant Formulations. Springer Netherlands, pp. $185-211$

Voulvoulis, N., Scrimshaw, M.D., Lester, J.N., 2000, Occurrence of four biocides utilized in antifouling paints, as alternatives to organotin compounds, in waters and sediments of a commercial estuary in the UK. Marine Pollution Bulletin 40, 938-946. 